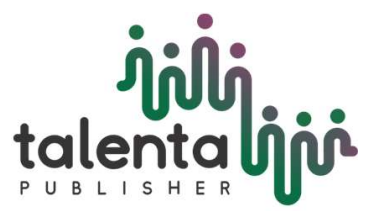

\title{
Isolation and Identification of Osmophilic Yeast from Unripe Jackfruit (Artocarpus heterophyllus Lamk.)
}

\author{
Nanik Suhartatik, Mimin Nurjanah, and Kapti Rahayu Kuswanto
}

Faculty of Technology and Food Industry, Slamet Riyadi University

\begin{abstract}
Osmophilic yeast are microbes that are able to live on media with high sugar concentrations. Some types of osmophilic yeast can break down organic compounds, for example, starch. This research was aimed to isolate and identify existing osmophilic yeast in unripe jackfruits. In this research, the unripe jackfruit was left rotting and $2.5 \mathrm{~g}$ of the sample were taken to be solved in $25 \mathrm{ml} 0.85 \% \mathrm{NaCl}$ and diluted. The GYP (glucose-yeast-peptone) agar medium with the glucose concentration of 30-50\% was suitable for osmophilic yeast growth. Isolate purification was performed using the streaking method from single colony. Isolates were identified based on physiological and morphological characteristics. The physiological characterization were carried out by running sugar assimilation test on the tool kit API 20C AUX, while the morphological characterization was carried out by performing macroscopic and microscopic observations. Four isolates were assumed to be Candida lambica, 3 isolates were assumed to be Candida rugosa and two isolates were assumed to be Geotrichum candidum. It was found out that $44.4 \%$ of yeast in the unripe jackfruit were Candida lambica, 33.3\% was Candida rugosa and 22.2\% was Geotrichum candidum. Candida lambica was the most common osmophilic yeast found in the jackfruit.
\end{abstract}

Keywords: identification, isolation, osmophilic yeast, unripe jackfruit Received 24 November 2018 | Revised 09 January 2019| Accepted 12 January 2019

\section{Introduction}

Jackfruit belongs to the genera Artocarpus. The pulp of this fruit was tasty and sweet. Generally, the jackfruit is consumed as slice form, fruits salad, mixture in cocktail, or preserved in sweetened or syrups. In particular, the unripe jackfruit was a based material in traditional culinary from Yogyakarta, called "gudeg". In some country, unripe jackfruit used as vegetable, especially to make curry or cooking with coconut milk. The term of unripe refers to the jackfruit that not been sweet in taste. According to [1], the major compound in jackfruit was carbohydrate (25.4\%) while the protein and fats were as low as $1.8 \mathrm{~g} / 100 \mathrm{~g}$ and $0.2 \mathrm{~g} / 100 \mathrm{~g}$, respectively.

The sugars content in fruits are able to support the growth of osmophilic yeast. Osmophilic yeast grows on media with a sugar level of 30-50\%, while osmotolerant yeast exists on media with a sugar level of $2-30 \%$ [2]. In previous research, osmophilic yeast were successfully isolated from

\footnotetext{
*Corresponding author at: Faculty of Technology and Food Industry, Slamet Riyadi University, Jl. Sumpah Pemuda 18 Joglo Kadipiro Surakarta, Middle java-Indonesia 57136

E-mail address: n_suhartatik@yahoo.com
} 
assorted high-sugar food products such as fruits, palm sugar, honey, jam and ketchup [3]. However, isolation and identification of the osmophilic yeast from tropical fruits, especially unripe jackfruits, are still underexplored.

Development in microbiology can be made through research on the isolation of microbes that may be used for food industry purposes. Indonesia is a country with a high degree of diversity in ecosystem, including the soil, plant, river, sea, among others. One of the ecosystems inhabited by microbes is plant. Fruit is a part of the plant that contains various organic compounds, making it a suitable habitat for microbes. In general, fruits have suitable $\mathrm{pH}$ for the growth of yeast and mold. Fruits typically have high levels of carbohydrates, such as fructose and glucose. The presence of sugar in fruits can trigger the growth of microbes of yeast type, especially osmophilic yeast [4]. The term "osmophilic" refer to the microorganism that could grow at high osmosis pressure, which could be set mainly by high sugar concentration.

Most of osmophile yeast plays an important role in food industry, such as Candida pelliculosa strain in condensed milk industry [5], Saccharomyces cerevisiae in bread making [6] or as prebiotics [7][8][9]; and also in the fermentation process [10]. The purpose of the research was to isolate osmophilic yeast from the deterioration process of unripe jackfruit. With many of osmophilic yeast's activities identified, it is necessary to conduct further research on the diversity of osmophilic yeast, which was expected to be useful for food industrial purposes in the future.

\section{Materials and Methods}

Unripe jackfruits were collected from local market. The jackfruit were then sliced into 4 pieces and left in the dark place for 7 to 10 days. Along with the deterioration process, the jackfruit was taken as a source of osmophilic yeast. A hundred milliliter of glucose-yeast-peptone (GYP) agar medium is composed of $2 \mathrm{~g}$ peptone, $20 \%$ glucose, $1 \mathrm{~g}$ yeast extract, 0.04 sodium bicarbonate; $0.004 \mathrm{~g}$ potassium phosphate; $0.004 \mathrm{~g}$ dipotassium phosphate; $0.008 \mathrm{~g} \mathrm{MgSO}_{4} ; 1.5 \mathrm{~g}$ agar powder and $0.01 \%$ chloramphenicol. Chemicals for GYP broth medium was purchased from SigmaAldrich Chemical Co (St. Louis, MO, USA). Sodium Chloride was purchased from Merck. All chemicals for analysis used in the study were of analytical grade. Osmophile yeast was isolated using $30 \%, 40 \%$ and $50 \%$ of glucose.

\subsection{Isolation Methods}

The osmophilic yeast isolation process was undertaken based on Kurtzman et al. [2]. The yeast identification process was studied based on the books "The Yeast. A Taxonomic Study" [11] and "Gideon Guide to Medically Important Yeasts: 2017 Edition" [12]. The osmophilic yeast isolates were confirmed through the growth on osmotic media tests. The osmophilic yeast isolates were identified for physiological characteristics using sugar assimilation test with tool kit API 20C AUX (Biomeriux, France) and morphological characteristics. 
Incision was made on a particular part of the unripe jackfruit, which was subsequently left rotting. As much as $2.5 \mathrm{~g}$ jackfruit was dissolved in $25 \mathrm{ml} 0.85 \%$ sodium chloride and was stirred slowly. A set of dilution was performed until reaching $10^{-6} \mathrm{CFU} / \mathrm{g}$, and isolates were grown by spread plating on solid glucose-yeast-peptone medium after being added with $0.01 \%$ chloramphenicol. Incubation was made at $30^{\circ} \mathrm{C}$ and $10^{\circ} \mathrm{C}$.

\subsection{Yeast Identification}

Yeast identification was performed on the yeast isolates successfully isolated from an unripe jackfruit using the sugar assimilation test, morphological test and growth test at $30^{\circ} \mathrm{C}$ and $10^{\circ} \mathrm{C}$. McFarland standard 2 was first made to find out the absorbance. Then, an osmophilic yeast suspension with the same absorbance as that of the McFarland standard 2 was prepared. As much as $2 \mathrm{ml}$ osmophilic yeast suspension was extracted and inserted into medium $\mathrm{C}$, then shaken until it turned homogenous. According to standard manual procedure of API 20C AUX (Biomerieux, France), medium $\mathrm{C}$ contain Ammonium sulfate $(5 \mathrm{~g})$, Monopotassium phosphate $(0.31 \mathrm{~g})$, Dipotassium phosphate ( $0.45 \mathrm{~g})$, Disodium phosphate ( $0.92 \mathrm{~g})$, Sodium chloride $(0.1 \mathrm{~g})$, Calcium chloride $0.05 \mathrm{~g}$ ), Magnesium sulfate (0.2 g), L-Histidine (0.005 g), L-Tryptophan (0.02 g), LMethionine $(0.02 \mathrm{~g})$, gelling agent $(0.5 \mathrm{~g})$, Vitamin solution $(1 \mathrm{ml})$, trace element $(10 \mathrm{ml})$, and demineralized water were added till the volume reach $1000 \mathrm{ml}$. The final $\mathrm{pH}$ of the medium $\mathrm{C}$ should be 6.4-6.8 at $20-25^{\circ} \mathrm{C}$. The sugar assimilation test was conducted using the tool kit API 20C AUX. Afterwards, $10 \mu 1$ mixture of osmophilic yeast suspension and medium $\mathrm{C}$ was poured into 20 cups containing 19 different types of sugar and 1 control. The control was medium $\mathrm{C}$ without any addition of any sugars as a carbon source. They were subsequently incubated at $30^{\circ} \mathrm{C}$ for $72 \mathrm{~h}$. Observation was performed by comparing isolate cells growing in the 19 different types of sugar and the isolate cells growing in the control. Positive results were showing with the turbid appearance in the cup within the tool kit API 20C AUX. The observation data was inputted to identification software for further analysis.

\subsection{Morphological Test}

Morphological observation was performed after the osmophilic yeast isolates were grown on the GYP agar medium according to treatment temperatures. Macroscopic observation was performed on the shape, size, color, margin, surface, elevation and texture of the colonies. The observation results were compared with the table of morphology of the osmophilic yeast's genus. Macroscopic observation was also performed by growing each isolate on solid medium to form a giant colony. It was then incubated for 30 days or more at treatment temperatures. Then, it was observed visually.

Microscopic observation was conducted by preparing slides. Clean slides were added with drops of $0.85 \% \mathrm{NaCl}$ solution. A small portion of the isolate colonies was taken using an inoculation loop and then smeared over the slides. A sufficient amount of lactophenol solution was added 
shortly after. The observation was assisted with a microscope at a 400x magnification. Microscopic observation was performed on the reproduction method, cell shape and presence of pseudohyphae/true hyphae (mycelium).

\section{Results and Discussion}

A total of 9 isolates were obtained from the isolation. The nine isolates were able to live on the osmotic media with glucose concentrations of $30 \%, 40 \%$ and $50 \%$. Hence, the nine yeast isolates were confirmed to be osmophilic. In the isolation and purification phases, selection was made based on the colonies growing on the $0.01 \%$ chloramphenicol-containing GYP medium. Chloramphenicol was used to inhibit the growth of bacteria. Initial isolate selection was based on the color, shape, diameter and thickness (transparency) of the colonies. Selected isolates were grown on osmotic media by streaking method. Purification was performed by streaking until truly pure solitary isolates were obtained.

The physiological characteristics of the 9 osmophilic yeast isolates along with their species was categorized using identification software (apiweb) (Table 1). According to Berger [12]," the species Candida lambica was able to assimilate glucose and n-acetyl-glucopyranoside at an ability level of $>90 \%$ and glycerol at an ability level of $10-90 \%$. It is also stated that Candida lambica does not assimilate xylose, on the other hand, Kreger-van Rij [11] states that the species Candida lambica was able to assimilate xylose.

Isolates IY2 and IY3 had some similarities in characteristics with Candida lambica, in which they were able to assimilate glucose, glycerol, xylose and n-acetyl-glucopyranoside. In addition, isolates IY6 and IY7 were only able to assimilate glucose, glycerol and xylose. There was a slight difference between the characteristics of isolates IY6 as well as IY7 and those of Candida lambica. According to Table 1, isolates IY6 and IY7 did not assimilate n-acetyl-glucopyranoside, while Candida lambica does. The characteristics as observed through the sugar assimilation test show that isolates IY2, IY3, IY6 and IY7 shared similarities with C. lambica. Thus, the four isolates were assumed to be Candida lambica.

According to Berger [12] the species Candida rugosa is known to be able to assimilate glucose, galactose and sorbitol at an ability level of $>90 \%$. Moreover, it can also assimilate glycerol, xylose, xylitol and n-acetyl-glucopyranoside at an ability level of 10-90\%. Based on the sugar assimilation test using API 20C AUX, isolates IY4, IY5 and IY9 demonstrated some similarities with the species Candida rugosa. Isolates IY4 and IY9 were able to assimilate glucose, glycerol, xylose, galactose, sorbitol and n-acetyl-glucopyranoside. Isolate IY5 was able to assimilate glucose, glycerol, xylose, xylitol, galactose and sorbitol. Therefore, based on the expressed on the physiological characteristics, isolates IY4, IY5 and IY9 were assumed to be Candida rugosa. 
Table 1. Physiological characteristics of the Isolates

\begin{tabular}{|c|c|c|c|c|c|c|c|c|c|c|c|c|}
\hline \multirow[b]{2}{*}{ Sugars } & \multicolumn{9}{|c|}{ Isolate Code } & \multicolumn{3}{|c|}{ Species } \\
\hline & IY1 & IY2 & IY3 & IY4 & IY5 & IY6 & IY7 & IY8 & IY9 & 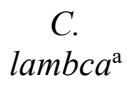 & $\begin{array}{c}\text { C. } \\
\text { rugosa }\end{array}$ & $\begin{array}{c}G . \\
\text { candidum }^{\mathrm{a}}\end{array}$ \\
\hline Glucose & + & + & + & + & + & + & + & + & + & + & + & + \\
\hline Glycerol & + & + & + & + & + & + & + & + & + & V & V & + \\
\hline $\begin{array}{l}\text { Calcium 2- } \\
\text { Keto- } \\
\text { Gluconate }\end{array}$ & - & - & - & - & - & - & - & - & - & - & - & - \\
\hline Arabinose & - & - & - & - & - & - & - & - & - & - & - & - \\
\hline Xylose & + & + & + & + & + & + & + & + & + & \pm & $\mathrm{V}$ & + \\
\hline Adonitol & - & - & - & - & - & - & - & - & - & - & - & - \\
\hline Xylitol & - & - & - & - & + & - & - & - & - & - & $\mathrm{V}$ & - \\
\hline Galactose & + & - & - & + & + & - & - & + & + & - & + & + \\
\hline Inositol & - & - & - & - & - & - & - & - & - & - & - & - \\
\hline Sorbitol & + & - & - & + & + & - & - & + & + & - & + & + \\
\hline $\begin{array}{l}\text { Methyl- } \alpha-D- \\
\text { Glucosamine }\end{array}$ & - & - & - & - & - & - & - & - & - & - & - & - \\
\hline $\begin{array}{l}\text { N-Acetyl- } \\
\text { Glucopyrano } \\
\text { side }\end{array}$ & - & + & + & + & - & - & - & - & + & + & V & - \\
\hline Cellobiose & - & - & - & - & - & - & - & - & - & - & - & - \\
\hline Lactose & - & - & - & - & - & - & - & - & - & - & - & - \\
\hline Maltose & - & - & - & - & - & - & - & - & - & - & - & - \\
\hline Sucrose & - & - & - & - & - & - & - & - & - & - & - & + \\
\hline Trehalose & - & - & - & - & - & - & - & - & - & - & - & - \\
\hline Melezitose & - & - & - & - & - & - & - & - & - & - & - & - \\
\hline Raffinose & - & - & - & - & - & - & - & - & - & - & - & - \\
\hline
\end{tabular}

Note: ${ }^{a}$ The Yeast. A Taxonomic Study (Kreger, 1984)

${ }^{\mathrm{b}}$ Gideon Guide To Medically Important Yeasts: 2017 Edition (Berger, 2017)

$(+)$ : Positive response/grow well ( $>90 \%)$

$(-)$ : Negative Response /not grow

(v) : small/less colony $(10-90 \%)$

$( \pm)$ : varies

According to Kreger van-Rijj [11] it is known that the species Geotrichum candidum is able to assimilate glucose, glycerol, xylose, galactose and sorbitol. Based on their physiological characteristics, isolates IY1 and IY8 were assumed to have some similarities with Geotrichum candidum. They were able to assimilate glucose, glycerol, xylose, galactose, sorbitol and sucrose at an ability level of $>90 \%$. However, there were a slight difference in the physiological characteristics between isolates IY1 as well as IY8 and the species G. candidum in terms of their ability to assimilate sucrose. The species G. candidum is able to assimilate sucrose, but both IY1 and IY 8 showed a negative response to this type of sugar. Given the physiological characteristics as shown from the sugar assimilation test, both IY1 and IY8 were assumed to be Geotrichum candidum.

Morphological characterization was performed through macroscopic and microscopic observations. Cell morphology was characterized by observing the cell shape, reproduction method and pseudohyphae/true hyphae formation. Meanwhile, macroscopic observation was performed by making a giant colony for each isolate. The giant colonies growing on petri dishes were observed for months and were observed to increase in diameters. The macroscopic 
characteristics observed include the shape, texture, color, surface, elevation and margin of the colonies [13]. Morphological observation was carried out after the isolates were incubated for 48 hours. Previous study demonstrated that during incubation period of 48-106 hours, isolates are in a growing period with their cells being in a juvenile state[11].

The comparison between the morphology of the isolates and that of Candida lambica is presented in Figure 1.

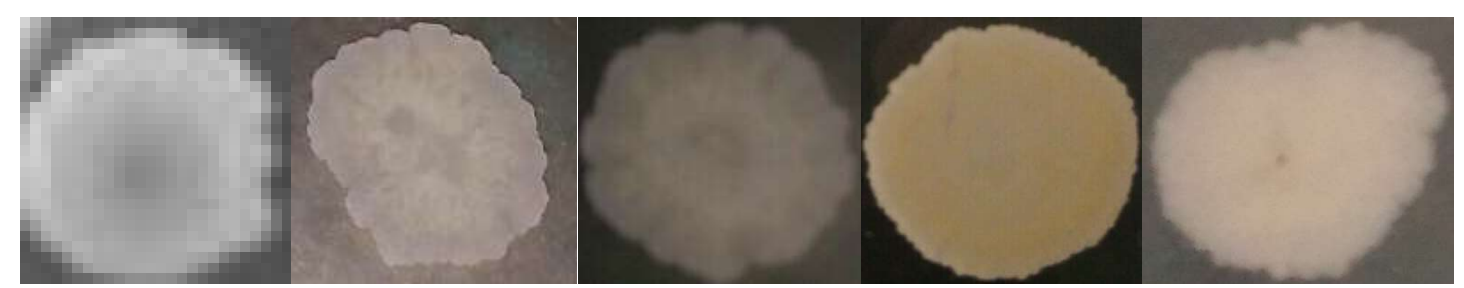

A

B

$\mathrm{C}$

$\mathrm{D}$

$\mathrm{E}$

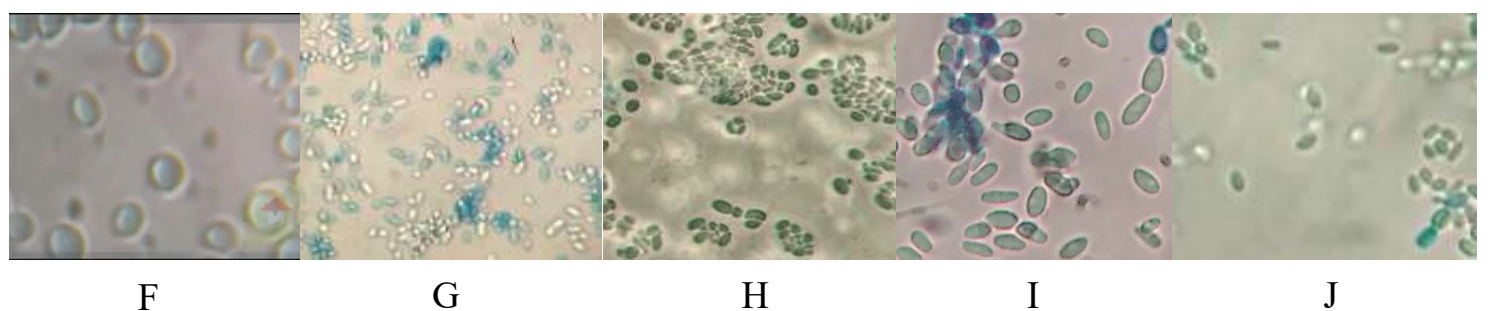

Figure 1. Morphological comparison between IY2, IY3, IY6, and IY7 with Candida lambica: (A) Colony of Candida lambica (http://www.doctrofungus.org/the fungi/Candida lambica.php); (B) IY2 isolate $\left(\mathrm{T}=30^{\circ} \mathrm{C}, 3 \mathrm{~h}\right)$; (C) IY3 isolate $\left(\mathrm{T}=30^{\circ} \mathrm{C}, 3 \mathrm{~h}\right)$; (D) IY6 isolate $\left(\overline{\mathrm{T}}=10^{\circ} \mathrm{C}, 12 \mathrm{~h}\right) ;(\mathrm{E})$ microscopic appearance of IY7 $\left(\mathrm{T}=10^{\circ} \mathrm{C}, 12 \mathrm{~h}\right) ;(\mathrm{F})$ Candida lambica; (G) IY2; (H) IY3; (I) IY6; (J) IY7. T = temperature for isolation procedure

Some differences were observed, including the size, shape, color, and the surface appearance. The colonies of isolates IY2 and IY7 had irregular shapes, while the colonies of the species Candida lambica take a circular form. Moreover, the colony of isolate IY6 was off-white in colour, while the colonies of Candida lambica are white to cream. The IY3 colony has more regular in shape and white. The diameters of isolates IY2, IY3, IY6 and IY7 colonies were 6, 5, 7 and $6 \mathrm{~mm}$, respectively. Kreger-van Rij (1984) stated that the species Candida lambica is assumed to have the ability to form pseudohyphae. In this research, isolates IY3, IY6 and IY7 formed pseudohyphae, while isolate IY2 did not. However, the formation of pseudohyphae should not use to identified genus because some aspects could affect the formation of pseudohyphae and based on individual prescription[14].

According to the morphological observations, the diameters of the colonies of isolates IY4, IY5 and IY9 were 6, 5 and $9 \mathrm{~mm}$, respectively. The comparison between the morphology of the isolates and that of Candida rugosa is presented in Figure 2. 


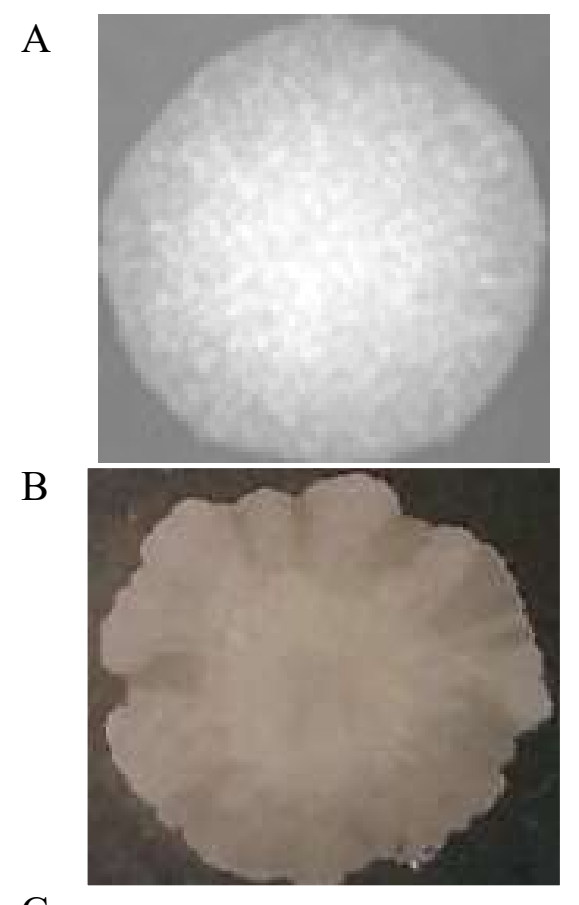

$\mathrm{C}$

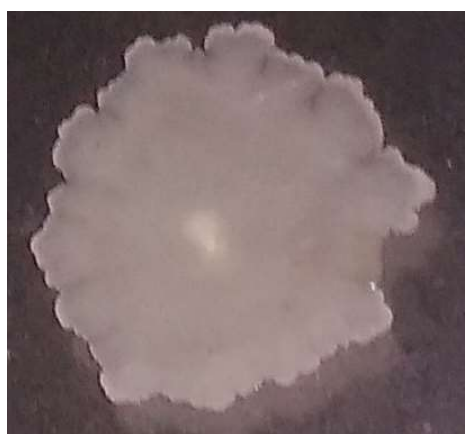

$\mathrm{D}$

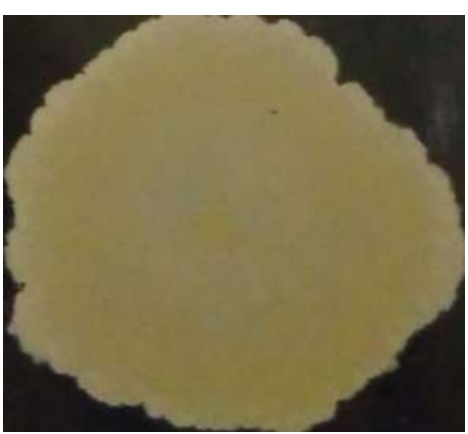

$\mathrm{E}$

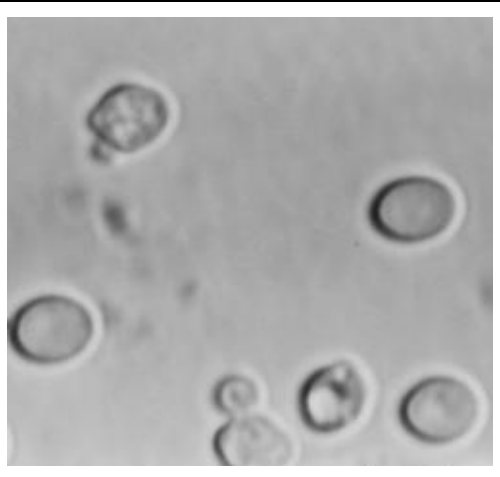

$\mathrm{F}$

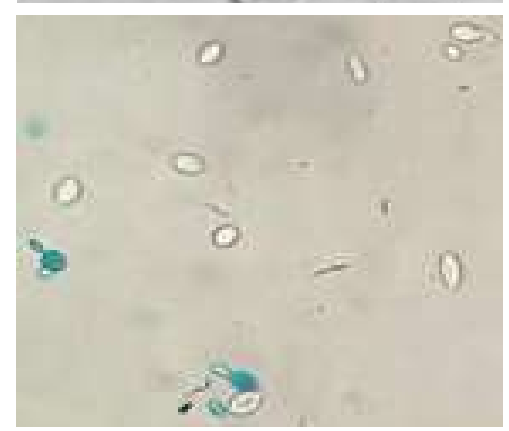

G

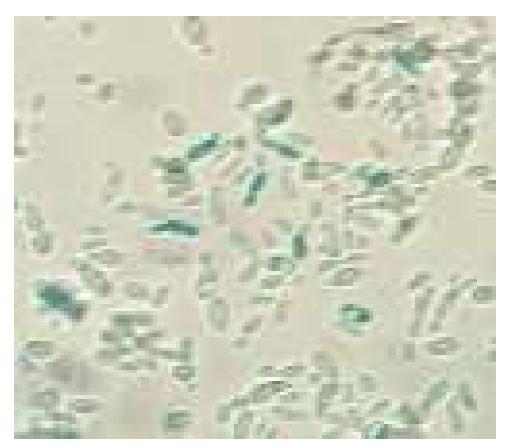

$\mathrm{H}$

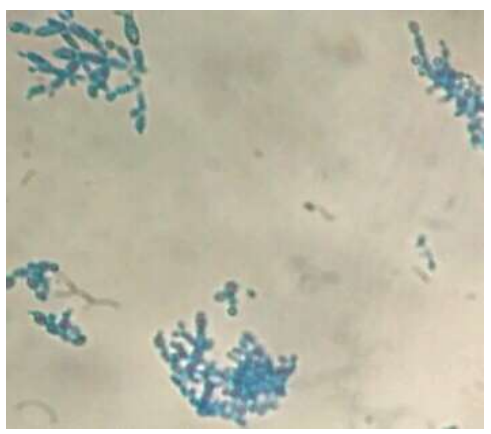

Figure 2. Morphological comparison between isolate IY4, IY5, and IY9 with Candida rugosa.

Notes: (A) Candida rugosa (http://jcm.asm.org/content/50/7/2397/F3.expansion.html); (B) Isolate IY4 $\left(\mathrm{T}=30^{\circ} \mathrm{C}, 3 \mathrm{~h}\right) ;(\mathrm{C})$ Isolate IY5 $\left(\mathrm{T}=30^{\circ} \mathrm{C}, 3 \mathrm{~h}\right) ;(\mathrm{D})$ Isolate IY9 $\left(\mathrm{T}=10^{\circ} \mathrm{C}, 12 \mathrm{~h}\right) ;(\mathrm{E})$ Microscopic appearance of C. rugosa (http://www.bcrc.firdi.org.tw/fungi/fungal_detail.jsp?id=FU200802060045); (F) Microscopic appearance of IY4; (G) Microscopic appearance of IY5; (H) Microscopic appearance of IY9.

There were some similarities in the morphological characteristics between isolate IY4 and Candida rugosa, but in terms of hyphae formation, there was a difference. According to Kreger-van Rij [11], the cells of Candida rugosa are able to form pseudohyphae, but isolate IY4 formed neither true hyphae nor pseudohyphae. According to the expressed morphological characteristics, isolate IY5 demonstrated a similarity with Candida rugosa, that is, both form pseudohyphae. However, IY5 forms a different colony shape 
than that of Candida rugosa. Candida rugosa has circular colonies, but the colony of isolate IY5 was irregular. Isolate IY9 also had similar morphological characteristics with those of Candida rugosa, but it had colonies in a different colour. The colony of isolate IY9 was yellow in colour, while the colony of Candida rugosa is off-white. The differences observed prove that isolates that can be identified using the sugar assimilation test are not necessarily identifiable based on their morphological characteristics.

According to the description above, out of the 9 isolates, 7 were assumed to be of the genus Candida. Based on the research by [3], the genus Candida is osmophilic. Isolates IY2, IY3, IY6 and IY7 were assumed to be Candida lambica. Isolates IY4, IY5 and IY9 were assumed to be Candida rugosa. Candida does not contain carotenoid, which making it appear to be white to cream. Candida is one of the genus that does not propagate sexually throughout its life cycle [15]. It was proven in this research that the 7 isolates assumed to belong to the genus Candida, as they did not propagate sexually. They propagated asexually by budding, instead. Buds are formed when parent cells have a tube-like bulge coming from the cell wall, which later forms a new yeast cell carrying complete genetic information.

The remaining isolates IY1 and IY8 showed some similarities with G. candidum, in terms of colony size, shape, and the color. Therefore, based on the expressed morphological characteristics, isolates IY1 and IY8 were assumed to be Geotrichum candidum. The genus Geotrichum has neither coniodospore nor pseudohyphae. Spores are formed by fragmentation of hyphae (arthrospore), they are hyaline, unicellular and of varied length and width. The genus Geotrichum has a rapid growth rate. The colony is flat, powdery or waxy, white and sexual. The comparison between the colonies and cells of isolates IY1 as well as IY8 and those of Geotrichum candidum are presented in Figure 3. 


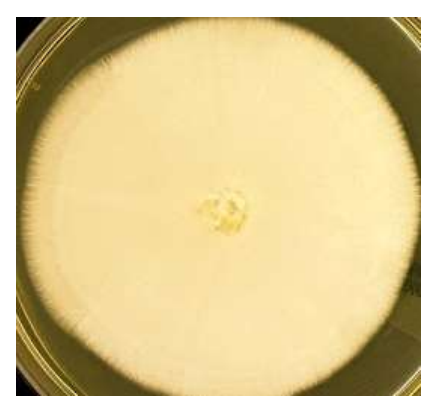

A

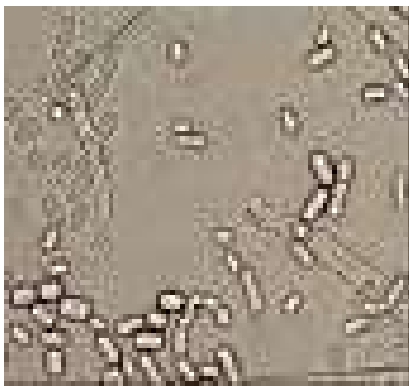

$\mathrm{D}$

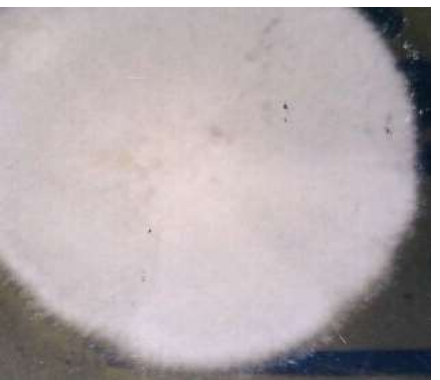

$\mathrm{B}$

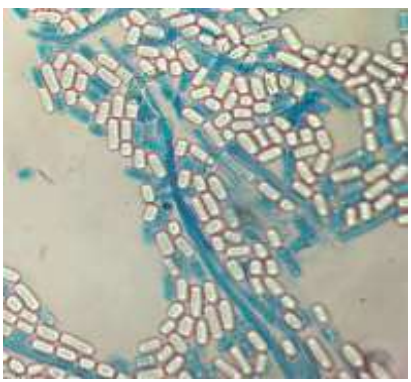

E

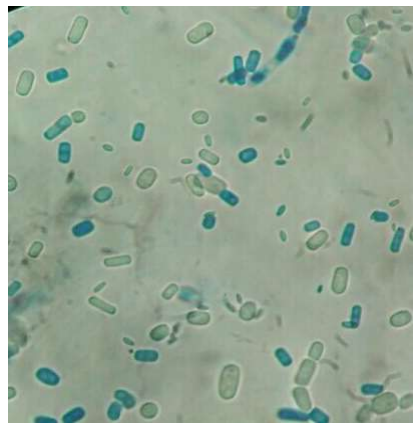

$\mathrm{F}$

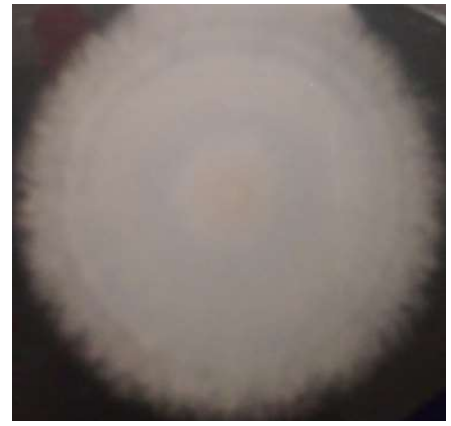

C

Fig 3. Morphological comparison of IY1 and IY8 isolate with Geotrichum candidum: (A)

Geotrichum candidum (http://thunderhouse4-yuri.blogspot.co.id/2012/05/geotrichumcandidum.html); (B) colony of IY1 $\left(30^{\circ} \mathrm{C}, 3 \mathrm{~h}\right)$; (C) colony form of IY8 $\left(10^{\circ} \mathrm{C}, 10 \mathrm{~h}\right)$; D) Cell of G.candidum (http://microbialfoods.org/geotrichum-candidum-mold-transition/); (E) Cell of IY1; (F) Cell of IY8

\section{Conclusions and Recommendation}

It can be concluded that the isolation of osmophilic yeast from an unripe jackfruit produced 9 isolates. Seven isolates were of the genus Candida, while the remaining 2 were of the genus Geotrichum. The isolates incubated at $30{ }^{\circ} \mathrm{C}$ grew more optimally than those incubated at $10{ }^{\circ} \mathrm{C}$. Based on the results of the physiological and morphological tests, isolates IY2, IY3, IY6 and IY7 were assumed to be Candida lambica, and isolates IY4, IY5 and IY9 were assumed to be Candida rugosa. Meanwhile, isolates IY1 and IY8 were assumed to be Geotrichum candidum. Of all isolates produced, $44.4 \%$ was were Candida lambica, 33.3\% was Candida rugosa and 22.2\% was Geotrichum candidum. However, the characteristics of the isolates obtained were not entirely identical with those of the assumed species.

Based on the research results, the following suggestions are presented: It is necessary to 
conduct further examination using DNA test to identify isolates more accurately. To be used as a starter culture for food industry purposes, it is necessary to conduct further research on the activity of the isolates obtained in the presence of various organic compounds. It is also necessary to carry out deeper review on the metabolism path of, and enzymes produced by, the isolates that were obtained.

\section{Acknowledgments}

Special thanks to Hisakazu Iino Sensei from Showa Women University of Tokyo for chemicals and guidance during the research.

\section{REFERENCE}

[1] Y. P. Tang, B. L. L. Linda, and L. W. Franz, "Proximate analysis of Artocarpus odoratissimus ( Tarap ) in,” Int. Food Res. J., vol. 20, no. 1, pp. 409-415, 2013.

[2] C. Kurtzman, J. Fell, T. Boekhout, and V. Robert, "Methods for Isolation, Phenotypic Characterization and Maintenance of Yeasts," in The Yeast, 3rd ed., Elsevier B.V., pp. 87110. 2011.

[3] B.S. Ridawati, Jenie, Itadjuwita, and W. Samsuridzal, "Genetic diversity of osmophilic yeasts isolated from indonesian foods with high concentration of sugar," J. Microbiol. Indones., vol. 4, no. 3, pp. 113-118, 2010.

[4] J. (Jeannie) Kim, E. Enache, and M. Hayman, "17 Halophilic and Osmophilic Microorganisms," Compend. Methods Microbiol. Exam. Foods, 2015.

[5] X. Xi-Lin, F. Guang-Li, L. Hong-Wei, L. Xiao-Feng, Z. Guang-lei, and X. Xing-Long, "Isolation, identification and control of osmophilic spoilage yeasts in sweetened condensed milk," African J. Microbiol. Res., vol. 8, no. 10, pp. 1032-1039, 2014.

[6] Z. Noroul Asyikeen, A. G. Ma'aruf, A. M. Sahilah, A. Mohd Khan, and W. M. Wan Aida, "A new source of Saccharomyces cerevisiae as a leavening agent in bread making," Int. Food Res. J., vol. 20, no. 2, pp. 967-973, 2013.

[7] P. Kaenpanao, P. Piwpan, and P. Jaturapiree, "Prebiotic fructooligosaccharide production from yeast strain ML1," Int. Food Res. J., vol. 23, no. 1, pp. 425-428, 2016.

[8] A. J. Al-Manhel and A. K. Niamah, "Mannan extract from Saccharomyces cerevisiae used as prebiotic in bioyogurt production from buffalo milk," Int. Food Res. J., vol. 24, no. 5, pp. 2259-2264, 2017.

[9] O. Nikitina, N. Cherno, S. Osolina, and K. Naumenko, "Yeast glucan and glucan-containing mushroom biopolymer complexes - stimulators of microflora growth," Int. Food Res. J., vol. 24, no. 6, pp. 2652-2659, 2017.

[10] I. L. Silva, M. A. Pahliarini, T. E. Chagas, M. Fruhauf, A. . Kempka, and R. C. Dornelles, "Effect of supplementation with pollen and brewer's yeast in the fermentation and in the physicochemical properties of honey spirits," vol. 24, no. June, pp. 1124-1134, 2017.

[11] N. J. . Kreger-van Rij, The Yeast. A Taxonomic Study. Elsevier B.V., 1984.

[12] S. Berger, Guide to Medically Important Yeast, 7th ed. California: Gideon Informatics Ltd, 2017.

[13] N. Widiastutik and H. Alami, "Isolasi dan Identifikasi Yeast dari Rhizosfer," J. Sains Dan Seni Pomits, vol. 3, no. 1, pp. 11-16, 2014. 
[14] F. C. Odds, M. G. Rinaldi, C. R. Cooper, A. Fothergill, and L. Pasarell, "Candida and Torulopsis: a Blinded Evaluation of Use of Pseudohypha Formation as Basis for Identification of Medically Important Yeasts," vol. 35, no. 1, pp. 313-316, 1997.

[15] T. Nakase, S. Matofumi, T. Masako, H. Makiko, H. Takushi, and F. Sakuzo, "A Taxonomic study on cellulotic yeasts and yeast-like microorganisms isolated in Japan I. Ascomycetous yeasts genera Candida and Williopsis, and a yeast-like genus Prototheca," J. Gen. Appl. Microbiol, vol. 40, pp. 519-531, 1994. 